\title{
TOPOLOGICAL STRUCTURAL ANALYSIS OF CHINA'S NEW ENERGY STOCK MARKET: A MULTI-DIMENSIONAL DATA NETWORK PERSPECTIVE
}

\author{
Kedong YIN ${ }^{1,2}$, Zhe LIU1 ${ }^{1}$ Chong HUANG ${ }^{1}$, Peide LIU \\ ${ }^{1}$ School of Economics, Ocean University of China, 266100 Qingdao Shandong, China \\ ${ }^{2}$ Ocean Development Research Institute, Major Research Base of Humanities and Social Sciences \\ of Ministry of Education, Ocean University of China, 266100 Qingdao Shandong, China \\ ${ }^{3}$ School of Management Science and Engineering, Shandong University of Finance and Economics, \\ 250014 Jinan Shandong, China
}

Received 02 November 2019; accepted 05 April 2020

\begin{abstract}
In this paper, we apply an RV coefficient network to investigate the topological structure of China's new energy stock market via daily prices of 60 component stocks of CSI (China Stock Index) New Energy Index spanning the period January 4, 2012 to March 29, 2019. Compared with the Pearson correlation coefficient, RV coefficient can better reflect the similarity between stocks from the perspective of multi-dimensional data. The empirical result indicates that (1) the scale-free characteristics of China's new energy stock market are not significant; (2) the new energy storage is the leading sub-sector of the new energy sector and the new energy interactive equipment plays a connecting role between renewable energy production and new energy storage; (3) the most influential stock in the network is Group DMEGC Magnetics Co., Ltd., Xiamen Tungsten Co., Ltd. and GEM Co., Ltd. play an important role in the network connection. These findings are of great significance to understand the interaction between Chinese new energy stocks and the pricing mechanism of stocks. The authority should pay more attention to the new energy storage industry. Investor's portfolios can be optimized according to the influence assessment of stocks and sub-sectors.
\end{abstract}

Keywords: new energy stock market, RV coefficient network, topological properties, minimum spanning tree.

JEL Classification: Q2, G12, D85, D53, C65.

\section{Introduction}

Since traditional fossil energy sources are depletable and cause a lot of pollution problems during use, in the past period, new energy sources have become the target of vigorous development in various countries (Wang et al., 2018). The continuous maturity of the new energy industry has a great impact on infrastructure construction (Gopalakrishnan \& Gkritza,

${ }^{\star}$ Corresponding author. E-mail: peide.liu@gmail.com 
2014), economic growth (Soava et al., 2018; Popescu et al., 2019) and sustainable development (Aceleanu et al., 2018), which has attracted the continuous attention of market investors (Chang \& Shieh, 2017). According to "Global Trends in Renewable Energy Investment" (Bloomberg New Energy Finance, 2018), since 2004, the cumulative investment in global renewable energy has reached 2.9 trillion US dollars, and the investment in 2017 was 279.8 billion US dollars, an increase of $15.8 \%$ compared with 2016. Bohl et al. (2013) pointed out that even the global financial crisis had only briefly affected the growth path of renewable energy investment, and its investment enthusiasm remained unchanged after the crisis.

As one of the emerging energy concepts, new energy also inherits the financial attributes of energy. It plays an important role not only in the energy sector but also in the financial market. Some scholars have studied the new energy stock market. Sadorsky (2012), Kumar et al. (2012), Managi and Okimoto (2013) studied the relationship between the prices of crude oil, clean energy stocks, and technology stocks. Bohl et al. (2013) studied the bubble behavior of German renewable energy company's stock prices and their influencing factors. Zhang and Du (2017) studied the relationship between the prices of China's new energy stocks, fossil fuel, and high-tech company stocks. Dutta et al. (2018) studied the linkage between carbon dioxide emissions and the return and volatility of clean energy stocks. Kazemilari et al. (2019) studied the network topology properties of US renewable energy companies based on stock returns.

In the past decade, China's new energy index prices have experienced dramatic fluctuations, especially when international crude oil futures prices change or China's macroeconomic policy adjustments (Wang et al., 2018). This development provides an interesting and unique environment for analyzing the overall development path of new energy-related listed companies and the mutual behavior between individuals. The rapid growth of China's economy has led to a huge domestic energy production gap, and external energy dependence has led to extensive discussions on energy security issues (Downs, 2004; Yao \& Chang, 2014). At the same time, the concept of sustainable development has been continuously strengthened in the development of the national economy. The Chinese government has promised to increase the proportion of non-fossil energy in the consumption of primary energy to about $20 \%$ by 2030 (He, 2015). These objective reasons have made the Chinese government pay more attention to the new energy-related industries in the formulation of energy policies so that more and more enterprises enter the new energy concept field. According to the " $\mathrm{BP}$ Statistical Review of world energy 2017” (BP, 2017), China has become the world's largest producer of renewable energy in 2016, the impact of the new energy industry on the macroeconomy has increased significantly.

The stock market is an extremely complex system, and its development process contains various interactions (Kazemilari \& Djauhari, 2015). Exogenous and endogenous shocks are transmitted in the system based on these linkages. The facts of the previous financial crisis prove that the comovement of stock markets at different levels plays an important role in the spread of risks. When the financial crisis occurred, the degree of stock market linkage rose rapidly, and the risk was quickly transmitted at different levels, which caused great pressure on monetary policy and market sentiment, and even led to severe economic recession (Garas \& Argyrakis, 2007; Roy \& Sarkar, 2011). The extraction and research of these mechanisms 
through the pricing behavior of the stock market, especially the identification of influential individuals and industries, is of great significance to the optimization of investors' portfolio and the risk management of market regulators.

From the perspective of the stock market or the sector as a whole, a large number of individuals and the information spillover relationship between them constitute a complex system. Therefore, it has become a reasonable choice to describe and analyze this complex system by constructing a complex network, in which each individual of the stock market is a network node, and the correlation between each other is regarded as the edge. Network science originated from graph theory, topology, and other branches of applied mathematics. With the successive development of Erdős-Rény (ER) random graph theory, small-world network, and scale-free network, complex networks have become an efficient system analysis tool (Fang et al., 2007), and are widely used in the research of many disciplines such as sociology, biology, and geoinformatics. Mantegna (1999) introduced the method into the financial market and studied the interaction between stocks through the minimum spanning tree method. Subsequently, complex network theory was widely used in financial market research, including the stock market, foreign exchange market, financial market risk.

Based on the 60 constituent stocks of the CSI New Energy Index, this paper analyzes the network topology characteristics of new energy-related listed companies in the Chinese stock market during 2012-2019. From the perspective of multidimensional data analysis, this paper adopts Escoufie’s RV coefficient (Escoufier, 1973; Robert \& Escoufier, 1976) which integrates the information of opening price, maximum price, minimum price and closing price of 60 stocks to construct the network adjacency matrix. Then, we analyze the overall characteristics of the network. Further, by constructing a minimum spanning tree, the centrality and hierarchical clustering structure of the network of new energy listed companies are studied. Finally, according to the classification criteria of the CSI New Energy Index for constituent stocks, 60 constituent stocks are divided into 12 sub-industries, and the topological characteristics of sub-industry networks are studied based on the minimum spanning tree method.

The contribution of this paper is threefold. First, this paper analyzes the network structure of China's new energy industry-related listed companies from the macro, meso, and micro levels. We verified the macro attributes of the new energy market stock based on the overall network and analyzed the core sub-sectors and core stocks from a meso and micro perspective based on the minimum spanning tree of the sub-sector network and stock network. These studies describe the network structure of China's new energy stock market in a three-dimensional way, which is of great significance to guide the implementation of policies and the construction of the investment portfolios. Secondly, this paper introduces relatively few applied RV correlation coefficients into the analysis of the new energy market stock network. The RV correlation coefficient can make better use of different types of stock price series, and fully extract the information contained in the data, so as to draw more accurate analysis conclusions. Third, although the literature has conducted extensive research on the network topology of the stock market, there has been relatively little research at the industry level, especially in the new energy industry. This article enriches the industry-level research results for the research on the network structure of new energy listed companies. On the other hand, the research of China's new energy industry is in its infancy, and the existing 
research perspectives focus on the substitution relationship and interaction between new energy and traditional energy (Wang et al., 2018). Based on the network structure, mining the pricing behavior and interaction mechanism of stocks from a data-driven perspective provides a new perspective for future research.

The remainder of this paper is organized as follows. Section 1 provides a literature review of network structure analysis. Sections 2 and 3 discuss the data set and the methodology we applied. In section 4, we present the principal empirical results and analyses. Last section concludes the paper.

\section{Literature review}

The network is the topological basis for the existence of a large number of complex systems. It abandons the small-scale details and pays more attention to its behavioral nature, providing a way to study complex systems. In this graph model, nodes stand for dynamic units, and the connections in the graph represent the interaction between them (Boccaletti et al., 2006). On the basis of the network, some statistical mechanics features are used to reveal these complex interactions, such as degree distribution, connectedness, diameter, and clustering coefficient (Albert \& Barabási, 2002).

Mantegna (1999) first introduced network science to the study of financial markets, and since then, complex networks have become a common tool for studying the interaction between assets. Kim et al. (2002) explored the correlation structure of the S\&P 500 stock price by a scale-free weighted network. Onnela et al. (2004) studied the network characteristics of 477 stocks on the New York Stock Exchange and analyzed its topological properties. Similar to Mantegna (1999), the minimum spanning tree is used to simplify the initial network in order to remove a large number of noises in the related structures. The same type of research also includes Jung et al. (2006), Garas and Argyrakis (2007), Wang et al. (2013), Majapa and Gossel (2016). Tumminello et al. (2005) pointed out that the structure of the minimum spanning tree is relatively simple, which means that there may be a situation of over-filtering leading to the loss of useful information, and proposed the method of plane maximum filter graph (PMFG). Tumminello et al. (2007) extracted the network topological characteristics of 300 stocks on the New York Stock Exchange based on the PMFG method. Aste et al. (2010) used the PMFG method to study the network of 395 stocks in the US and identifies the impact of the subprime crisis on the network structure. In addition, the threshold method can also simplify a network by removing the correlation below the threshold. Huang et al. (2009) evaluated the robustness of the Chinese stock market and its ability to resist external shocks based on the threshold method. Nobi et al. (2014) considered the effects of the 2008 global financial crisis of a local Korean financial market based on threshold networks.

With the abundance of network analysis methods, the calculation methods of the correlation matrix in the process of network construction are gradually diversified. The traditional construction method of the correlation matrix is the Pearson correlation coefficient (PCC) (Bonanno et al., 2003; Brida \& Risso, 2008; Galazka, 2011). The PCC-based complex network is intuitive and simple, and can better reflect the static linkage between variables. In order to better characterize the dynamic evolution of network features, the DCC-MVGARCH model 
(Engle, 2002) was introduced to characterize the dynamic conditional correlation between individuals (Lyócsa et al., 2012; Qiao et al., 2016; Yin et al., 2017). The above method is only for the measurement of the individual feature correlation between variables, but each individual has multidimensional features in real life, such as stock prices. Kazemilari and Djauhari (2015) proposed a correlation matrix method based on the RV coefficient (Escoufier, 1973; Robert \& Escoufier, 1976) from the perspective of multidimensional data, and demonstrated the superiority of RV coefficient with respect to PCC. This adjacency matrix construction method is widely used in the fields of economics (Djauhari \& Gan, 2016) and finance (San Yee et al., 2018).

Complex networks have become a mature tool for stock market structure research, but there are relatively few research results at the industry level, especially for research between listed companies in the new energy industry. Kazemilari et al. $(2017,2019)$ extracted the topological characteristics between US renewable energy listed companies and identified core companies and core sub-sectors of the renewable energy sector in different periods. The research on the network structure between listed companies in China's new energy sector has not been widely carried out. Wang et al. (2018) pointed out that the research on China's new energy industry is still in its infancy, and the research perspective is mainly based on its alternative relationship and mutual influence between traditional energy sources. Therefore, measuring the similarity between listed companies in China's new energy industry and further studying the network characteristics of these listed companies is crucial for identifying the core companies of the new energy industry and revealing the price movement rules of the new energy industry.

\section{Data}

Our sample consists of daily observations of 60 constituent stocks in the CSI New Energy Index spanning the period from January 4, 2012 to March 29, 2019. The data for each stock includes opening, highest, lowest and closing prices after split-adjusted. These data sets are extracted from the Wind information database.

The CSI New Energy Index takes the remaining stocks of Shanghai and Shenzhen Ashares as the sample space after excluding special treatment stocks and stocks with a time to market less than three months. Eighty stocks of listed companies in the new energy-related business are selected as constituent stocks to reflect the overall performance of listed companies in the new energy industry. The benchmark date for the Index is December 31, 2011, with a base point of 1000. Since the issuance of the index, CSI New Energy Index has become the subject of many stock index funds.

In order to describe the new energy sector rationally, this paper takes the constituent shares of the CSI New Energy Index over the years as the sample space to screen stocks. The selected sample stock satisfies the requirement that each stock has been a component of the index since its release and contains at least 150 observations per year. Eventually, 60 stocks are selected. For the same reason, the starting point of the sample's observation interval is the same as the release date of the index.

In order to study the relationship between sub-sectors, analogous to Kazemilari et al. (2019), this paper divides the sample stocks into sub-sectors according to the business areas 
of 60 listed companies and the industry classification criteria of CSI New Energy Index. The sub-industries are divided into 11 categories: Solar, Wind, Nuclear, Solar and Wind, Wind and Nuclear, Water and Nuclear, Storage, Solar and Storage, Interactive Equipment, Storage and Interactive Equipment, Comprehensive. The stock codes, company full names and subindustry classifications of 60 sample stocks are listed in the appendix.

\section{Methodology}

\subsection{RV coefficient network}

We use the RV coefficient network proposed by Kazemilari and Djauhari (2015) to realize multi-dimensional data analysis of the new energy market. Since each stock has four price vectors as OHLC, we extend the idea of the logarithmic rate of change to each price sequence as

$$
R_{i}(t, k)=\ln P_{i}(t, k)-\ln P_{i}(t-1, k), i=1,2, \cdots, n, t=1,2, \cdots, N, k=1,2,3,4,
$$

where $R_{i}(t, k)$ denote the log change of stock $i$ at time $t$ for price series $k$. When $k$ is equal to 1 , it represents the opening price series. Similarly, 2 represents the highest price, 3 represents the lowest price, and 4 represents the closing price.

Then, the covariance between the $k$ th log change of price $i$ and the $l$ th log change of price $j$ can be calculated as

$$
c_{i j}(k, l)=E_{t}\left(R_{i}(t, k) R_{j}(t, l)\right)-E_{t}\left(R_{i}(t, k)\right) E_{t}\left(R_{j}(t, l)\right), k, l=1,2,3,4,
$$

where $E_{t}(\bullet)$ is the average for all $t$, and $k, l$ represents the price sequence type. Therefore, there are 16 different types of covariance between stock $i$ and $j$. Reshaping 16 covariances of stock $i$ and $j$ into a $4^{\star} 4$ matrix $C_{i j}$, where $c_{i j}(k, l)$ is the element of row $i$ and column $j$ in the matrix, then matrix $C_{i j}$ can be proved satisfying the positive semidefinite condition. According to Escoufier (1973), Robert and Escoufier (1976), we have the RV coefficient between stock $i$ and $j$ as

$$
R V_{i j}=\frac{\operatorname{trace}\left\{C_{i j}^{T} C_{i j}\right\}}{\sqrt{\left(\operatorname{trace}\left\{C_{i i}^{T} C_{i i}\right\}\right)\left(\operatorname{trace}\left\{C_{j j}^{T} C_{j j}\right\}\right)}},
$$

where trace $\{\bullet\}$ means the sum of all diagonal elements of a rectangular matrix.

Following the above steps, we calculate the RV coefficients between each pair of stocks in the sample space and construct the connection matrix of the network. Obviously, the matrix is symmetric. Furthermore, as a general method of network construction, each stock in the sample space is regarded as a network node, and the RV coefficient between nodes is used as the connection weight, we construct the stock network of China's new energy market from the perspective of multi-dimensional data.

\subsection{Minimum spanning tree}

The minimum spanning tree is a subgraph of a weighted undirected connected graph, which satisfies that all nodes are connected, without any loops, and the sum of weights of all edges is minimal. 
In order to extract the minimum spanning tree, the RV coefficient matrix is first transformed into the distance matrix, referring to Mantegna (1999). The transformation formula is as follows:

$$
d_{i j}=\sqrt{2\left(1-R V_{i j}\right)} .
$$

On the basis of the distance between any two nodes in a complex network, the minimum spanning tree can be solved. Among these methods, the Prim algorithm (Prim, 1957) and the Kruskal algorithm (Kruskal, 1956) are commonly used. The Kruskal algorithm is chosen to realize the minimum spanning tree. The main steps of the algorithm are as follows: first, Sort the edges in the network according to the order of weight, and the least weighted edges are selected to join the spanning tree. Then, the least weighted edges of the remaining edges are added to the spanning tree. The edge can be retained if the newly added edge does not result in a cycle in the tree. Repeat these steps until the spanning tree contains $(n-1)$ edges for a graph with $n$ nodes.

\subsection{Network topological properties}

Degree and degree distribution are the basic nature of the network. The degree is a concept that describes the attributes of a single node. For weightless graphs, the degree of node $i$ is the number of edges connected to node $i$. While for the weighted graphs, the degree of node $i$ equals the sum of the weights of all edges connected to node $i$. Intuitively, the greater the degree of the node, the higher the importance of the node. Since the network in this paper is a weighted network, the weighted node degrees are used for the measure of node degrees. It is defined as

$$
W D_{i}=\sum_{\substack{j=1 \\ i \neq j}}^{n} w_{i j}, i=1,2, \cdots, n,
$$

where $w_{i j}$ denotes the weight of the connection between nodes $i$ and $j$. The weight distribution difference measures the dispersion degree of the edge weight connected with node $i$, which can be calculated by

$$
D D_{i}=\sum_{j}\left(w_{i j} / W D_{i}\right)^{2} .
$$

In order to reflect the overall characteristics of the node degree, the distribution of degree is expressed by a distribution function $P(k) . P(k)$ indicates the proportion of the number of nodes with a $k$-degree in the network to the total number of network nodes. Literatures on the degree distribution have shown that networks in different fields follow a power-law model, i.e., $P(k) \propto k^{-\gamma}$ or $\log P(k) \propto-\lambda \log k$ (Aiello et al., 2001; Hayes, 2000). Boginski et al. (2005) showed that the US financial market network obeys power-law distribution.

Network centrality is also one of the fundamental concepts in network analysis (Borgatti, 2005). This paper mainly studies the degree of centrality and median centrality of the network. Degree centrality mainly measures the level of connectivity between nodes (Nieminen, 1974). Analogous to the concept of node degree, nodes with higher degrees of centrality also have a greater impact on the network. The degree centrality can be calculated through the following formula: 


$$
C D_{i}=\frac{\operatorname{deg}(i)}{n-1}
$$

where $\operatorname{deg}(i)$ denotes the number of links adjacent to stock $i$.

Another centrality measure in this paper is the betweenness centrality (Freeman, 1977). The betweenness of node $i$ is the ratio of the number of shortest paths through node $i$ to the number of all shortest paths in a network, which can be expressed as

$$
B_{i}=\sum_{s \neq t \neq i} \frac{\sigma_{s t}(i)}{\sigma_{s t}},
$$

where $\sigma_{s t}$ denotes the number of shortest paths between nodes $s$ and $t$ and $\sigma_{s t}(i)$ is the number of shortest paths between nodes $s$ and $t$ passing through node $i$. In practical applications, the betweenness centrality is usually normalized, that is, the median divided by the vertex logarithm of the vertex itself. The measure is

$$
C B_{i}=\frac{2}{(n-1)(n-2)} \sum_{s \neq t \neq i} \frac{\sigma_{s t}(i)}{\sigma_{s t}} .
$$

The importance of nodes depends not only on their own characteristics but also on their location in the network. On the basis of the weak tie theory (Granovetter, 1973), Burt (1992) puts forward the structure hole theory in network analysis. The structural hole index mainly considers four aspects: effective scale, efficiency, constraint and hierarchy, among which the constraint is the most important. The constraint is the ability of a node to utilize structural holes in a network. The formula for computing the constraint of node $i$ to node $j$ is

$$
S H_{i j}=\left(p_{i j}+\sum_{q \neq i, j} p_{i q} p_{q j}\right)^{2},
$$

where $p_{i j}$ is the proportion of node $i$ spent on its relationship with the directly connected node $j, p_{i q} p_{q j}$ denotes the redundancy between node $i$ and $j$. The total constraint of node $i$ is defined as

$$
S H_{i}=\sum_{j \neq i} S H_{i j} .
$$

The constraint of a node measures the ability of a node to utilize structural holes. The smaller the constraint degree, the greater the degree of structural holes, and the more structural holes it may occupy. On the contrary, the greater the degree of constraint, the smaller the probability of occupying structural holes.

The structural hole theory is mainly used in the analysis of social networks. It emphasizes that structural holes in interpersonal networks can bring information and other resources advantages to organizations and individuals in this position. For the stock market, each stock is equivalent to the individual in the society, and the correlation between stocks is consistent with the social network structure. Therefore, structural hole theory is also applicable in stock market analysis. In addition to the individual characteristics of stocks, this paper also analyzes the status and role of individual stocks or sub-industries in the overall network from the perspective of structural holes. 


\section{Empirical results}

\subsection{Overall characteristics of new energy market network}

Before the specific analysis of individual stocks or sub-industries, we first give a general overview of the whole new energy market network. In such a manner, the new energy market network on the basis of the RV coefficient calculated from OHLC prices is constructed.

Corresponding to the RV coefficient matrix, the distribution of correlation coefficients is shown in Figure 1. It's clear that the correlation among 60 stocks in the new energy sector is quite different, only some stocks have a relatively high correlation. The RV coefficients between nodes obey the normal distribution approximately, with a mean of 0.1963 and a variance of 0.0695 . The minimum value is -0.0121 , which means that there exists a pair of nodes with a negative correlation of price information. In addition, there are some pairs of nodes with relatively high correlation, which located on the right side of the distribution, but the overall number is small.

Based on the basic information of the network, the first subject of our interests is the degree distribution characteristics of the new energy market network under different thresholds, especially whether it obeys the power-law distribution with the increase of thresholds, just like the financial markets involved in some existing studies. Figure 2 shows the degree distribution under partial thresholds and the power-law distribution parameters corresponding to these thresholds are shown in Table 1.

Similar to Boginski et al. (2005), the degree distribution of the new energy network does not present any well-defined structure with a relatively small threshold. In fact, even if the threshold is increased to 0.3 , the distribution of node degree cannot satisfy Poisson distribution. When the threshold value increases to 0.35 , the network presents a more significant power-law distribution structure with a gamma of 0.6311 . This feature is maintained at a higher threshold level. In the distribution of RV coefficients, 0.35 is a relatively high threshold

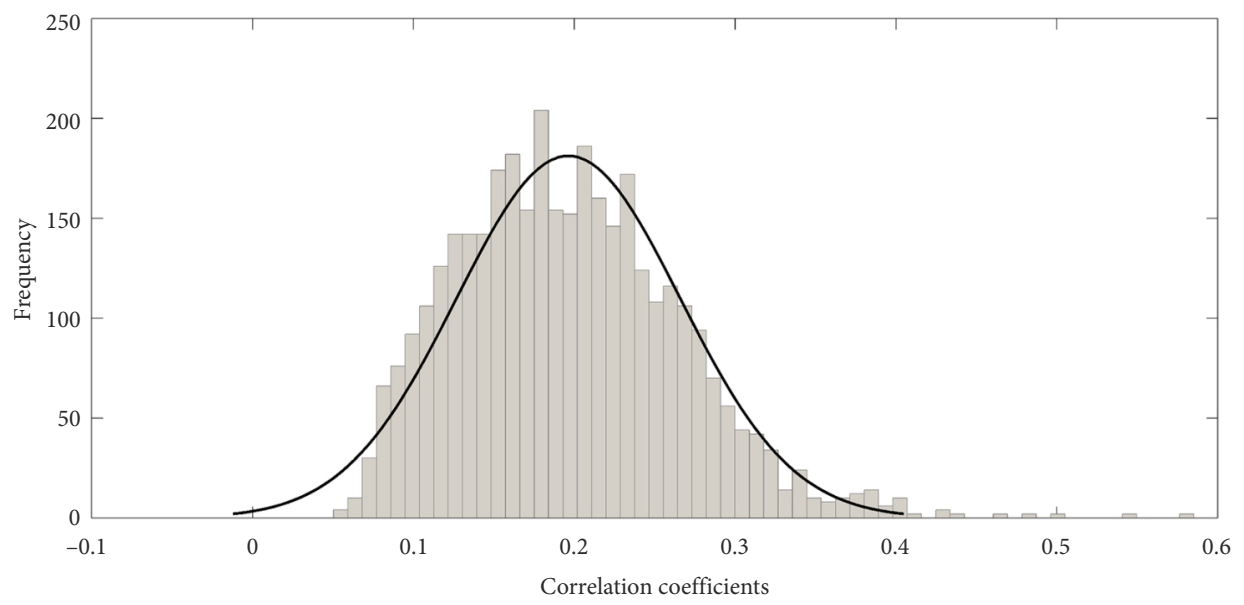

Figure 1. Distribution of correlation coefficients in new energy market 
and only a few nodes and connections remained in the network. On the other hand, compared with the S\&P stock network which presents a power-law distribution with an average gamma of 1.8, the slope of the new energy market network is very small under different thresholds. Therefore, the scale-free characteristics of the new energy market network are not very significant.

The insignificant scale-free nature means that the price data of new energy industryrelated stocks do not show high heterogeneity. Although some nodes with a high degree of node exist in the network, they are not significantly higher in the network hierarchy than other nodes. At this time, the method of constructing portfolios based on gang sets and independent sets may fail, and it is relatively difficult to construct independent sets. At the same time, the insignificant scale-free nature also makes the transmission of random risk more widely in the listed companies of the new energy industry, and it is easy to form a relatively large rise or fall.
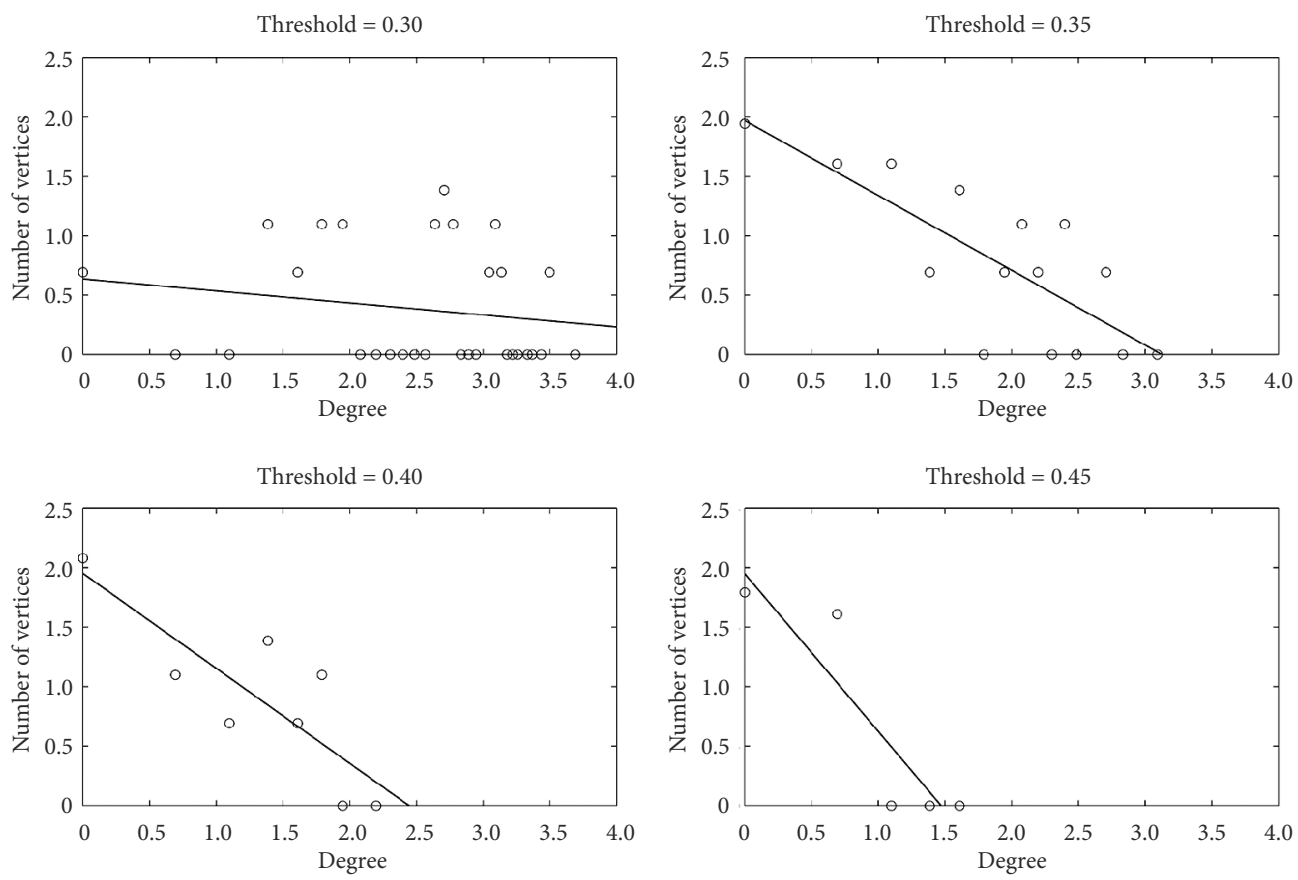

Figure 2. Degree distribution under different thresholds (logarithmic scale)

Table 1. Power law distribution parameters for different thresholds

\begin{tabular}{|c|c|c|c|c|}
\hline Threshold & 0.30 & 0.35 & 0.40 & 0.45 \\
\hline Gamma & 0.1013 & 0.6311 & 0.7991 & 1.3253 \\
\hline
\end{tabular}




\subsection{Network analysis of new energy stocks based on MST}

Based on the overall understanding of the new energy market network structure, it is of great significance to further identify influential stocks and sub-sectors. The MST approach is used to simplify the network and some properties of nodes, including degree centrality, betweenness centrality, and constraint degree, are used to comprehensively evaluate their influence. We use the R package "igraph" (Csardi \& Nepusz, 2006) to realize the visualization of the network.

The minimum spanning tree of 60 new energy market stocks' network is shown in Figure 3 . Every stock is colored according to its sub-sector classification. Different from the research of Kazemilari et al. (2019), the minimum spanning tree of China's new energy market does not have a significant number of connections of the same type of nodes. The distribution of stocks related to renewable energy production is quite scattered, especially.

The information transfer characteristics of China's new energy industry listed companies can be found in Figure 3. A large number of listed companies related to new energy storage are gathered in the lower left, while the upper right is mainly renewable energy production

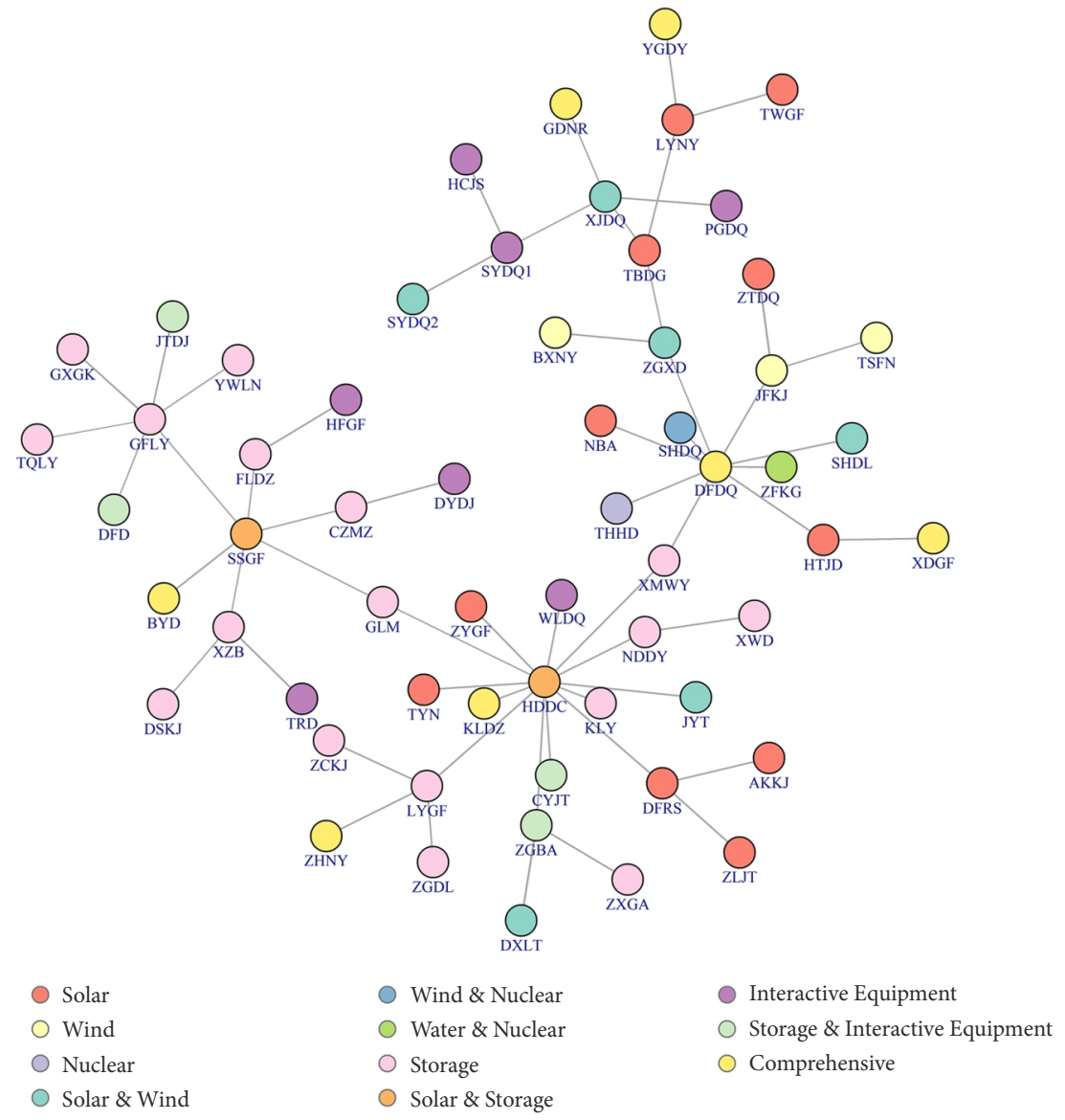

Figure 3. Minimum spanning tree of 60 new energy stocks network 
companies. As the minimum spanning tree representing the fastest information transmission path between nodes to a certain extent, according to Figure 3, the exchange of stock price information between renewable energy production companies and new energy storage companies is relatively slow, while the information transmission efficiency in the two sub-sectors is higher. In addition, compared with listed companies in renewable energy production, the connection structure of new energy storage companies is significantly more complex, which covers renewable energy production, new energy interactive equipment, and integrated industries. This means that the listed companies of renewable energy production are relatively single and have less ability to withstand risks, while new energy storage companies can extend the industrial chain to both ends and effectively diversify risks with other sub-sectors.

Based on the minimum spanning tree, we calculate the degree centrality, the betweenness and the constraint degree of the structure hole of each stock. The top 10 influential stocks based on these topological indicators are shown in Table 2. Hengdian Group DMEGC Magnetics Co., Ltd. (HDDC) is considered the most influential stock as it connects to stocks in many different sub-sectors. A higher betweenness indicates that HDDC plays an important role in market information transmission, while the lowest degree of constraint represents that HDDC occupies an important structural hole position and has good stability in the face of a non-systemic crisis.

In addition, the other two companies of interest are GEM Co., Ltd. (GLM) and Xiamen Tungsten Co., Ltd. (XMWY). Relative to other influential stocks, the degree of centrality of these two stocks is very small. However, they constitute the two most important triples in the network, namely "HDDC-XMWY-DFDQ" and "HDDC-GLM-SSGF". HDDC, DFDQ (Dongfang Electric Co., Ltd.) and SSGF (Ningbo Shanshan Co., Ltd.) play an important role in the market, especially they all have a high degree of centrality. As the only connecting node among them, GLM and XMWY have a high level of betweenness centrality and play an important role in ensuring the information transmission of the whole network.

The results in Table 2 show that the businesses of listed companies with high influence are mostly related to sub-sectors such as new energy storage and solar energy. Therefore, for investors, investment in new energy stocks should focus on policy changes, scientific research progress, and investor sentiment in the new energy storage industry and the solar industry.

Table 2. The top 10 influential stocks and topological indicators

\begin{tabular}{|l|l|c|c|c|}
\hline \multicolumn{1}{|c|}{ Stock } & \multicolumn{1}{c|}{ Sub-sector } & Degree & Betweenness & Constraint \\
\hline HDDC & Solar \& Storage & 0.220 & 0.761 & 0.077 \\
\hline DFDQ & Comprehensive & 0.153 & 0.570 & 0.111 \\
\hline SSGF & Solar \& Storage & 0.102 & 0.410 & 0.167 \\
\hline GFLY & Storage & 0.102 & 0.164 & 0.167 \\
\hline XJDQ & Storage & 0.068 & 0.162 & 0.250 \\
\hline LYGF & Storage & 0.068 & 0.100 & 0.250 \\
\hline LYNY & Solar \& Wind & 0.051 & 0.067 & 0.333 \\
\hline XZB & Solar & 0.051 & 0.067 & 0.333 \\
\hline GLM & Storage \& Interactive Equipment & 0.034 & 0.386 & 0.500 \\
\hline XMWY & Wind & 0.034 & 0.484 & 0.500 \\
\hline
\end{tabular}


In addition, this result also shows that China's current non-solar renewable energy production is relatively insufficient, and the development of new energy interactive equipment also has a lot of room for improvement.

Estimating the importance of sub-sector based on stock level topological characteristics may exist bias. In addition to influential stocks, the aggregation level of stocks also determines the importance of the sub-sector. We measure the agglomeration level of the subsector from the stock cluster perspective. A random walks algorithm is used to do the classify and the result is shown in Figure 4. Different from Figure 3, nodes in Figure 4 are marked as the serial number, and the corresponding sub-sector names are shown in the legend. The 60 stocks are divided into 11 community structures with different nodal numbers. Storage and solar are two categories with obvious clustering characteristics. These two sub-industries are located in several adjacent communities and play a major role in each community. As for solar \& storage, there are only a few nodes and they distribute in two different communities, which reduces the influence of individual stocks.

\subsection{Network analysis of new energy sub-sectors based on MST}

In order to identify the underlying preferred sub-sector more accurately, the topological structure of the sub-sector network is further analyzed. The OHLC data for each sub-sector are calculated by the arithmetic average of the stock prices which include in it. The MST method is also used to simplify the network and the result is shown in Figure 5. Different colored nodes represent different types of subsectors, and the width of the edge is proportional to the distance between the two points.

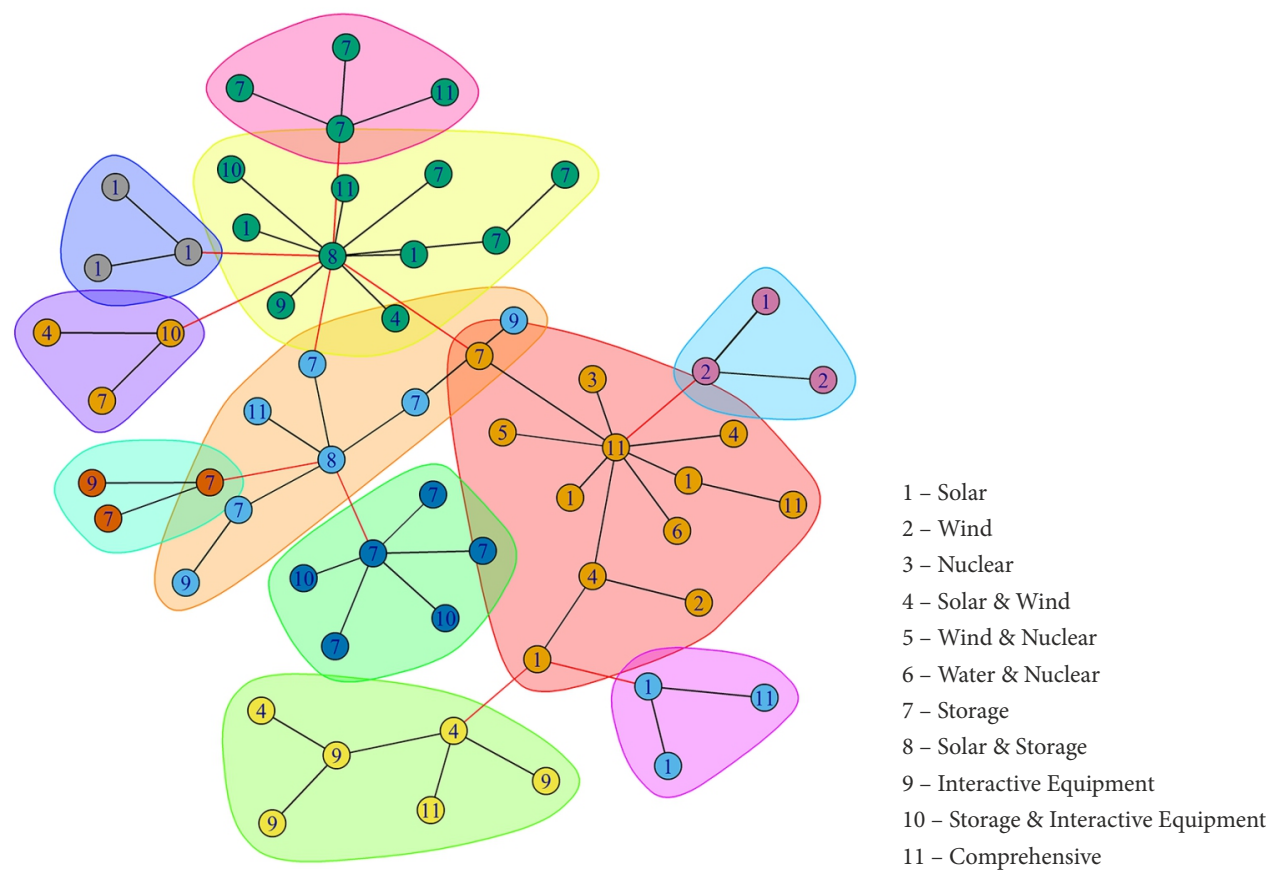

Figure 4. Community structures of new energy market 
Similar to the structure based on stock, the top left corner of the minimum spanning tree based on sub-industry is mainly renewable energy production, and the bottom right corner is multi-industry with new energy storage as the core. This also shows that our data conversion method is reasonable. We calculated the topological characteristics of 11 nodes, and the results of the top five sub-sectors are shown in Table 3.

Figure 6 shows the distribution of edge distance weights of different nodes in the form of a boxplot. In the network, distance determines the efficiency of information transmission. From the distribution of the distance between nodes, the top five nodes can be divided into two categories: one is interactive equipment, solar and storage, the other is solar \& wind and comprehensive. The range between nodes of the first sub-sector category is small, while that of the second category is relatively large. From the perspective of the median of distance

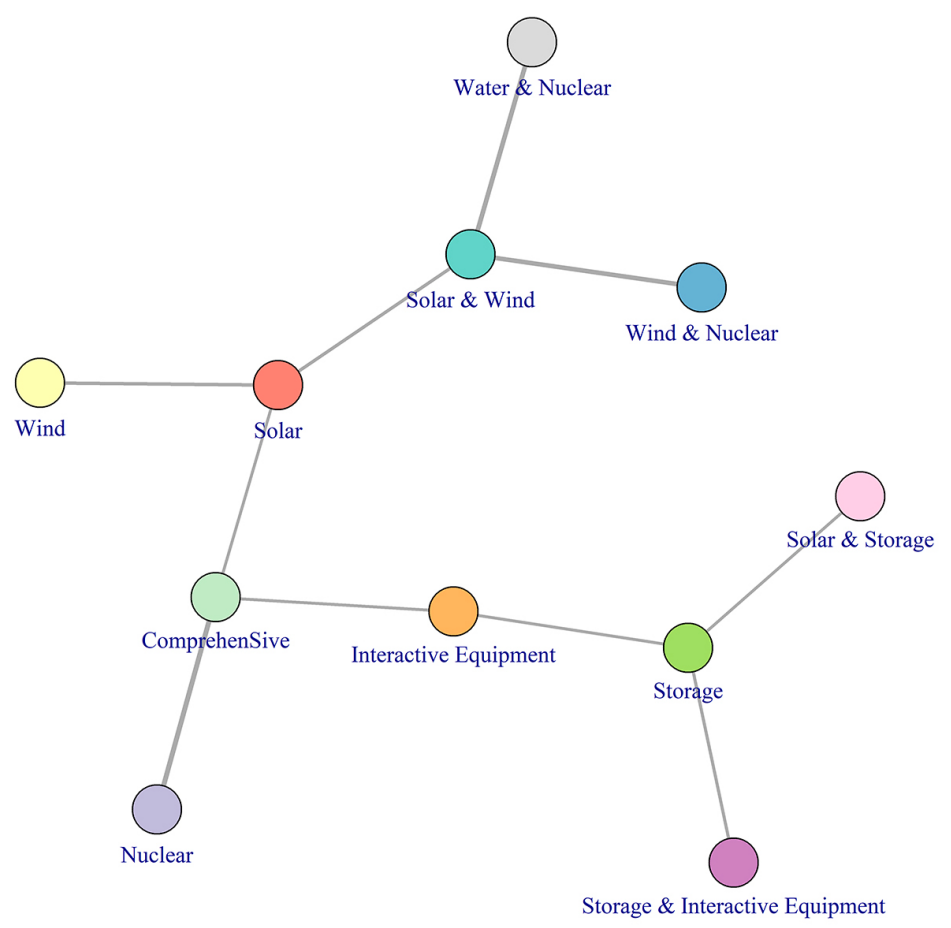

Figure 5. Minimum spanning tree of 11 new energy sub-sector network

Table 3. The top 5 influential sub-sectors and topological indicators

\begin{tabular}{|l|c|c|c|}
\hline \multicolumn{1}{|c|}{ Sub-sector } & Degree & Betweenness & Constraint \\
\hline Comprehensive & 0.3 & 0.644 & 0.333 \\
\hline Solar & 0.3 & 0.600 & 0.333 \\
\hline Storage & 0.3 & 0.378 & 0.333 \\
\hline Solar \& Wind & 0.3 & 0.378 & 0.333 \\
\hline Interactive Equipment & 0.2 & 0.467 & 0.500 \\
\hline
\end{tabular}


distribution, both the sub-sectors of storage, interactive equipment, comprehensive and solar have a small median, which means they have high information transmission efficiency. The only special sub-sector is solar \& wind, although it also has a high degree of nodes, the distance between it and other nodes is large, the median is relatively high, and the efficiency of information transmission is low.

Combined with Table 3 and Figure 6, the leading sub-industry of the whole new energy industry is new energy storage. New energy interactive equipment plays a role in connecting renewable energy production and new energy storage. The core of renewable energy production is solar. The sensitivity of wind energy-related stocks to information is close to that of solar energy, but the sensitivity of water energy and nuclear energy-related stocks to information is relatively low, especially nuclear energy. The characteristics of these companies are conducive to building a decentralized portfolio from the sub-sector level. For the government, besides paying attention to the importance of the sub-sectors, they can further accelerate the implementation of policies form the perspective of information transmission efficiency when they introduce related industry stimulus policies.

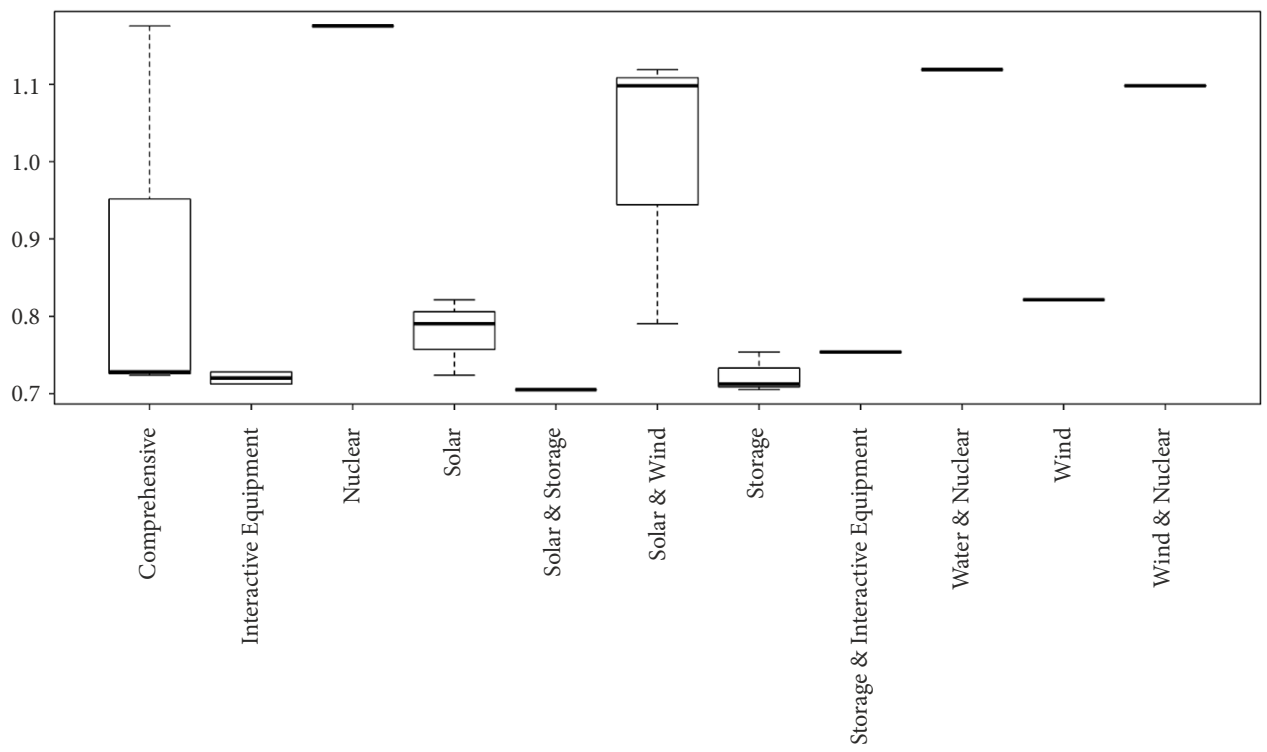

Figure 6. The distance distribution between different nodes in sub-sector MST

\section{Conclusions}

The rapid development of China's new energy industry has attracted extensive attention from investors, which has significantly increased the importance of the new energy industry in the stock market. In the past decade, stocks related to renewable energy production, new energy storage, and new energy interactive equipment have experienced dramatic fluctuations. The unique background and policy environment make these characteristics of the new energy industry different from the traditional industries. In order to better evaluate the interaction 
mechanism between stocks in the new energy industry, the most important thing is to identify important individuals and sub-sectors based on existing price information.

Therefore, this paper focuses on the research of China's new energy industry from the perspective of stocks and sub-sectors. The network structure of stocks and sub-sectors are presented among 60 constituent stocks' OHLC prices of CSI New Energy Index from January 4, 2012 to March 29, 2019. As with most financial network research, we first study the scale-free nature of stock networks in new energy markets. Then, networks of stocks and sub-sectors are simplified by the minimum spanning tree method. From the perspectives of centrality, structural holes, industry aggregation, and distance, the most influential stocks and sub-sectors were identified.

Our research shows that the scale-free characteristics of China's new energy market stock network are not significant, even at higher thresholds, there are still many nodes with higher node degrees. Research on the minimum spanning tree of the stock market network shows that Hengdian Group DMEGC Magnetics Co., Ltd. is the most influential stock in the new energy sector. It has the most connections with other stocks, plays an important information hub in network information transmission, and has the strongest ability to use other stocks for information transmission. There are two important ternary structures as "HDDC-XMWYDFDQ" and "HDDC-GLM-SSGF" in the network. Xiamen Tungsten Co., Ltd. and GEM Co., Ltd. are respectively the only central nodes of the above structure, which also make them have an important position in the network. The new energy storage is recognized as the most influential sub-section of the new energy industry. At the same time, the new energy interactive equipment plays a connecting role between renewable energy production and new energy storage. Solar energy is the core of renewable energy production. Besides, both the researches based on stocks or sub-sections show that, the linkage between companies with renewable energy production as their core business and companies that develop diversified businesses with new storage as the core has a significant boundary.

This paper analyzes the network topology of China's new energy market from the perspective of multi-dimensional data. Although related methods have been widely used in financial markets, there are relatively few studies on new energy industries. Mining information within the market from a network structure framework can better examine and understand the behavior of industrial systems. for investors, there is no significant scale-free feature, which means that the stock prices of the listed companies may have strong synchronicity. The identification of important stocks and sub-sectors shows that investors should focus on new energy storage sub-sectors and solar sub-sectors, while the linkage between sub-sectors such as hydropower, nuclear energy, and other sub-sectors is relatively low. This information can provide a reference for investment. For the government, the identification of core stocks and core sub-industries is also of great significance. In the short term, the current policy-making should focus on the development of new energy storage, and make it drive the development of new energy interactive equipment and other industries. At the same time, the government should further stimulate the diversity of renewable energy production, especially improve the utilization level of wind energy and water energy. In the long run, the government should further promote the integration of industries and improve the efficiency of new energy from production to storage to application. 
Future research can be carried out in the following ways. First, although this paper considered the perspective of multi-dimensional data, the networks are still undirected. It is of practical significance to study the topological structure of China's new energy industry based on univariable or multivariable directed network, especially its dynamic evolution process. Secondly, it is worthwhile to take a closer look at the impact of China's new energy policy on the structure of the stock network and its information transmission behavior.

\section{Acknowledgements}

This research is supported by the National Social Science Found Major Projects (14ZDB151); National Science Foundation of China under Grants (41701593, 71371098, 71571157); National Key Research and Development Program of China (Grant No. 2016YFC1402000).

\section{References}

Aceleanu, M. I., Șerban, A. C., Țîrcă, D. M., \& Badea, L. (2018). The rural sustainable development through renewable energy. The case of Romania. Technological and Economic Development of Economy, 24(4), 1408-1434. https://doi.org/10.3846/20294913.2017.1303650

Aiello, W., Chung, F., \& Lu, L. (2001). A random graph model for power law graphs. Experimental Mathematics, 10(1), 53-66. https://doi.org/10.1080/10586458.2001.10504428

Albert, R., \& Barabási, A. (2002). Statistical mechanics of complex networks. Reviews of Modern Physics, 74(1), 47. https://doi.org/10.1103/RevModPhys.74.47

Aste, T., Shaw, W., \& Di Matteo, T. (2010). Correlation structure and dynamics in volatile markets. New Journal of Physics, 12(8), 85009. https://doi.org/10.1088/1367-2630/12/8/085009

Bloomberg New Energy Finance. (2018). Global trends in renewable energy investment 2018. UNEP United Nations Environment Programme, Bloomberg New Energy Finance. http://www.iberglobal.com/files/2018/renewable_trends.pdf

Boccaletti, S., Latora, V., Moreno, Y., Chavez, M., \& Hwang, D. U. (2006). Complex networks: Structure and dynamics. Physics Reports, 4-5(424), 175-308.

https://doi.org/10.1016/j.physrep.2005.10.009

Boginski, V., Butenko, S., \& Pardalos, P. M. (2005). Statistical analysis of financial networks. Computational Statistics \& Data Analysis, 48(2), 431-443.

https://doi.org/10.1016/j.csda.2004.02.004

Bohl, M. T., Kaufmann, P., \& Stephan, P. M. (2013). From hero to zero: Evidence of performance reversal and speculative bubbles in German renewable energy stocks. Energy Economics, 37, 40-51. https://doi.org/10.1016/j.eneco.2013.01.006

Bonanno, G., Caldarelli, G., Lillo, F., \& Mantegna, R. N. (2003). Topology of correlation-based minimal spanning trees in real and model markets. Physical Review E, 68(4), 46130. https://doi.org/10.1103/PhysRevE.68.046130

Borgatti, S. P. (2005). Centrality and network flow. Social Networks, 27(1), 55-71. https://doi.org/10.1016/j.socnet.2004.11.008

BP. (2017). BP Statistical Review of world energy June, 2017. British Petroleum. http://large.stanford.edu/courses/2018/ph241/kuet2/docs/bp-2017.pdf

Brida, J. G., \& Risso, W. A. (2008). Multidimensional minimal spanning tree: The Dow Jones case. Physica A: Statistical Mechanics and its Applications, 387(21), 5205-5210. https://doi.org/10.1016/j.physa.2008.05.009 
Burt, R. (1992). Structural holes: the social structure of competition. Harvard University Press.

Chang, M. C., \& Shieh, H. S. (2017). The relations between energy efficiency and GDP in the Baltic Sea Region and Non-Baltic Sea Region. Transformations in Business \& Economics, 16(2), 235-247.

Csardi, G., \& Nepusz, T. (2006). The igraph software package for complex network research. InterJournal, Complex Systems, 1695(5), 1-9.

Djauhari, M. A., \& Gan, S. L. (2016). Network topology of economic sectors. Journal of Statistical Mechanics: Theory and Experiment, 2016(9), 93401. https://doi.org/10.1088/1742-5468/2016/09/093401

Downs, E. S. (2004). The Chinese energy security debate. The China Quarterly, 177, 21-41. https://doi.org/10.1017/S0305741004000037

Dutta, A., Bouri, E., \& Noor, M. H. (2018). Return and volatility linkages between CO2 emission and clean energy stock prices. Energy, 164, 803-810. https://doi.org/10.1016/j.energy.2018.09.055

Engle, R. (2002). Dynamic conditional correlation: A simple class of multivariate generalized autoregressive conditional heteroskedasticity models. Journal of Business \& Economic Statistics, 20(3), 339-350. https://doi.org/10.1198/073500102288618487

Escoufier, Y. (1973). Le traitement des variables vectorielles. Biometrics, 29(4), 751-760. https://doi.org/10.2307/2529140

Fang, J. Q., Wang, X. F., Zheng, Z. G., Bi, Q., Zeng, R. D., \& Li, X. (2007). New interdisciplinary science: Network science (1). Progress in Physics, 27(3), 239.

Freeman, L. (1977). A set of measures of centrality based on betweenness. Sociometry, 40(1), 35-41. https://doi.org/10.2307/3033543

Galazka, M. (2011). Characteristics of the polish stock market correlations. International Review of Financial Analysis, 20(1), 1-5. https://doi.org/10.1016/j.irfa.2010.11.002

Garas, A., \& Argyrakis, P. (2007). Correlation study of the Athens Stock Exchange. Physica A Statistical Mechanics \& Its Applications, 380(7), 399-410. https://doi.org/10.1016/j.physa.2007.02.097

Gopalakrishnan, K., \& Gkritza, K. N. (2014). Forecasting transportation infrastructure impacts of renewable energy industry using neural networks. Technological and Economic Development of Economy, 19(Supplement_1), S157-S175. https://doi.org/10.3846/20294913.2013.876690

Granovetter, M. (1973). The strength of weak ties. American Journal of Sociology, 78, 1360-1380. https://doi.org/10.1016/B978-0-12-442450-0.50025-0

Hayes, B. (2000). Computing science: Graph theory in practice: Part I. American Scientist, 88(1), 9-13. https://doi.org/10.1511/2000.1.9

He, J. (2015). China's INDC and non-fossil energy development. Advances in Climate Change Research, 6(3-4), 210-215. https://doi.org/10.1016/j.accre.2015.11.007

Huang, W. Q., Zhuang, X. T., \& Yao, S. (2009). A network analysis of the Chinese stock market. Physica A: Statistical Mechanics and its Applications, 388(14), 2956-2964. https://doi.org/10.1016/j.physa.2009.03.028

Jung, W. S., Chae, S., Yang, J. S., \& Moon, H. T. (2006). Characteristics of the Korean stock market correlations. Physica A: Statistical Mechanics and its Applications, 361(1), 263-271.

https://doi.org/10.1016/j.physa.2005.06.081

Kazemilari, M., Mohamadi, A., Mardani, A., \& Streimikis, J. (2019). Network topology of renewable energy companies: minimal spanning tree and sub-dominant ultrametric for the American stock. Technological and Economic Development of Economy, 25(2), 168-187. https://doi.org/10.3846/tede.2019.7686

Kazemilari, M., \& Djauhari, M. A. (2015). Correlation network analysis for multi-dimensional data in stock market. Physica A: Statistical Mechanics and its Applications, 429, 62-75.

https://doi.org/10.1016/j.physa.2015.02.052 
Kazemilari, M., Mardani, A., Streimikiene, D., \& Zavadskas, E. K. (2017). An overview of renewable energy companies in stock exchange: Evidence from minimal spanning tree approach. Renewable Energy, 102(Part A), 107-117. https://doi.org/10.1016/j.renene.2016.10.029

Kim, H. J., Lee, Y., Kahng, B., \& Kim, I. (2002). Weighted scale-free network in financial correlations. Journal of the Physical Society of Japan, 71(9), 2133-2136. https://doi.org/10.1143/JPSJ.71.2133

Kruskal, J. B. (1956). On the shortest spanning subtree of a graph and the traveling salesman problem. Proceedings of the American Mathematical society, 7(1), 48-50. https://doi.org/10.2307/2033241

Kumar, S., Managi, S., \& Matsuda, A. (2012). Stock prices of clean energy firms, oil and carbon markets: A vector autoregressive analysis. Energy Economics, 34(1), 215-226. https://doi.org/10.1016/j.eneco.2011.03.002

Lyócsa, Š., Výrost, T., \& Baumöhl, E. (2012). Stock market networks: the dynamic conditional correlation approach. Physica A: Statistical Mechanics and its Applications, 391, 4147-4158. https://doi. org/10.1016/j.physa.2012.03.038

Majapa, M., \& Gossel, S. J. (2016). Topology of the South African stock market network across the 2008 financial crisis. Physica A: Statistical Mechanics and its Applications, 445, 35-47. https://doi.org/10.1016/j.physa.2015.10.108

Managi, S., \& Okimoto, T. (2013). Does the price of oil interact with clean energy prices in the stock market? Japan and the World Economy, 27, 1-9. https://doi.org/10.1016/j.japwor.2013.03.003

Mantegna, R. N. (1999). Hierarchical structure in financial markets. The European Physical Journal B-Condensed Matter and Complex Systems, 1(11), 193-197. https://doi.org/10.1007/s100510050929

Nieminen, J. (1974). On the centrality in a graph. Scandinavian Journal of Psychology, 15(1), 332-336. https://doi.org/10.1111/j.1467-9450.1974.tb00598.x

Nobi, A., Lee, S., Kim, D. H., \& Lee, J. W. (2014). Correlation and network topologies in global and local stock indices. Physics Letters A, 378(34), 2482-2489. https://doi.org/10.1016/j.physleta.2014.07.009

Onnela, J. P., Kaski, K., \& Kertész, J. (2004). Clustering and information in correlation based financial networks. The European Physical Journal B, 38(2), 353-362.

https://doi.org/10.1140/epjb/e2004-00128-7

Popescu, G. H., Andrei, J. V., Nica, E., Mieilă, M., \& Panait, M. (2019). Analysis on the impact of investments, energy use and domestic material consumption in changing the Romanian economic paradigm. Technological and Economic Development of Economy, 25(1), 59-81. https://doi.org/10.3846/tede.2019.7454

Prim, R. C. (1957). Shortest connection networks and some generalizations. The Bell System Technical Journal, 36(6), 1389-1401. https://doi.org/10.1002/j.1538-7305.1957.tb01515.x

Qiao, H., Xia, Y., \& Li, Y. (2016). Can network linkage effects determine return? Evidence from Chinese stock market. Plos One, 11(6), e1567846. https://doi.org/10.1371/journal.pone.0156784

Robert, P., \& Escoufier, Y. (1976). A unifying tool for linear multivariate statistical methods: the RV-coefficient. Journal of the Royal Statistical Society: Series C (Applied Statistics), 25(3), 257-265. https://doi.org/10.2307/2347233

Roy, R. B., \& Sarkar, U. K. (2011). Identifying influential stock indices from global stock markets: A social network analysis approach. Procedia Computer Science, 5, 442-449. https://doi.org/10.1016/j.procs.2011.07.057

Sadorsky, P. (2012). Correlations and volatility spillovers between oil prices and the stock prices of clean energy and technology companies. Energy Economics, 34(1), 248-255.

https://doi.org/10.1016/j.eneco.2011.03.006

San Yee, L., Salleh, R. M., \& Asrah, N. M. (2018). Multidimensional minimal spanning tree: the bursa Malaysia. Journal of Science and Technology, 10(2). 
Soava, G., Mehedintu, A., Sterpu, M., \& Raduteanu, M. (2018). Impact of renewable energy consumption on economic growth: evidence from European union countries. Technological and Economic Development of Economy, 24(3), 914-932. https://doi.org/10.3846/tede.2018.1426

Tumminello, M., Aste, T., Di Matteo, T., \& Mantegna, R. N. (2005). A tool for filtering information in complex systems. Proceedings of the National Academy of Sciences, 102(30), 10421-10426. https://doi.org/10.1073/pnas.0500298102

Tumminello, M., Aste, T., Di Matteo, T., \& Mantegna, R. N. (2007). Correlation based networks of equity returns sampled at different time horizons. The European Physical Journal B, 55(2), 209-217. https://doi.org/10.1140/epjb/e2006-00414-4

Wang, C., Chen, Y., \& Jin, X. (2018). Research on the effect of International oil price pass-through on the China's new energy market. The Journal of Quantitative \& Technical Economics, (4), 131-146.

Wang, G. J., Xie, C., Chen, Y. J., \& Chen, S. (2013). Statistical properties of the foreign exchange network at different time scales: evidence from detrended cross correlation coefficient and minimum spanning tree. Entropy, 15(5), 1643-1662. https://doi.org/10.3390/e15051643

Yao, L., \& Chang, Y. (2014). Energy security in China: a quantitative analysis and policy implications. Energy Policy, 67, 595-604. https://doi.org/10.1016/j.enpol.2013.12.047

Yin, K. D., Liu, Z., \& Liu, P. D. (2017). Trend analysis of global stock market linkage based on a dynamic conditional correlation network. Journal of Business Economics and Management, 18(4), 779-800. https://doi.org/10.3846/16111699.2017.1341849

Zhang, G., \& Du, Z. (2017). Co-movements among the stock prices of new energy, high-technology and fossil fuel companies in China. Energy, 135, 249-256.

https://doi.org/10.1016/j.energy.2017.06.103 


\section{APPENDIX}

Table A shows the detail information of 60 components of CSI New Energy Index, including constituent code, constituent name, constituent abbreviation and the sub-sector each stock belong.

Table A

\begin{tabular}{|c|c|c|c|c|}
\hline No & Code & Abbreviation & Constituent name & Sub-sector \\
\hline 1 & 000009 & ZGBA & China Baoan Group Co.,Ltd. & $\begin{array}{l}\text { Storage \& Interactive } \\
\text { Equipment }\end{array}$ \\
\hline 2 & 000012 & NBA & CSG Holding Co.,Ltd. & Solar \\
\hline 3 & 000040 & DXLT & $\begin{array}{l}\text { Tunghsu Azure Renewable Energy } \\
\text { Co.,Ltd. }\end{array}$ & Solar \& Wind \\
\hline 4 & 000400 & XJDQ & XJ Electric Co.,Ltd. & Solar \& Wind \\
\hline 5 & 000591 & TYN & Cecep Solar Energy Co.,ltd. & Solar \\
\hline 6 & 000690 & BXNY & $\begin{array}{l}\text { Guangdong Baolihua New Energy Stock } \\
\text { Co.,ltd. }\end{array}$ & Wind \\
\hline 7 & 000839 & ZXGA & $\begin{array}{l}\text { CITIC Guoan Information Industry } \\
\text { Co.,Ltd. }\end{array}$ & Storage \\
\hline 8 & 002028 & SYDQ1 & Sieyuan Electric Co.,ltd. & Interactive Equipment \\
\hline 9 & 002056 & HDDC & $\begin{array}{l}\text { Hengdian Group DMEGC Magnetics } \\
\text { Co.,Ltd. }\end{array}$ & Solar \& Storage \\
\hline 10 & 002074 & GXGK & Guoxuan High-Tech Co.,Ltd. & Storage \\
\hline 11 & 002080 & ZCKJ & Sinoma Science \& Technology Co.,Ltd. & Storage \\
\hline 12 & 002108 & CZMZ & Cangzhou Mingzhu Plastic Co.,Ltd. & Storage \\
\hline 13 & 002121 & KLDZ & Shenzhen Clou Electronics Co.,Ltd. & Comprehensive \\
\hline 14 & 002176 & JTDJ & Jiangxi Special Electric Motor Co.,Ltd. & $\begin{array}{l}\text { Storage \& Interactive } \\
\text { Equipment }\end{array}$ \\
\hline 15 & 002202 & JFKJ & $\begin{array}{l}\text { Xinjiang Goldwind Science\&Technology } \\
\text { Co.,Ltd. }\end{array}$ & Wind \\
\hline 16 & 002249 & DYDJ & Zhongshan Broad-Ocean Motor Co.,Ltd. & Interactive Equipment \\
\hline 17 & 002266 & ZFKG & Zhefu Holding Group Co.,Ltd. & Nuclear \& Water \\
\hline 18 & 002309 & ZLJT & Jiangsu Zhongli Group Co.,Ltd. & Solar \\
\hline 19 & 002340 & GLM & GEM Co.,Ltd. & Storage \\
\hline 20 & 002358 & SYDQ2 & Henan Senyuan Electric Co.,Ltd. & Solar \& Wind \\
\hline 21 & 002366 & THHD & $\begin{array}{l}\text { Taihai Manoir Nuclear Equipment } \\
\text { Co.,Ltd. }\end{array}$ & Nuclear \\
\hline 22 & 002407 & DFD & Do-fluoride Chemicals Co.,Ltd. & $\begin{array}{l}\text { Storage \& Interactive } \\
\text { Equipment }\end{array}$ \\
\hline 23 & 002460 & GFLY & Ganfeng Lithium Co., Ltd. & Storage \\
\hline 24 & 002466 & TQLY & Tianqi Lithium Co., Ltd. & Storage \\
\hline 25 & 002531 & TSFN & Titan Wind Energy (Suzhou) Co.,Ltd. & Wind \\
\hline 26 & 002594 & BYD & BYD Co., Led. & Comprehensive \\
\hline
\end{tabular}


End of Table $A$

\begin{tabular}{|c|c|c|c|c|}
\hline No & Code & Abbreviation & Constituent name & Sub-sector \\
\hline 27 & 002610 & AKKJ & $\begin{array}{l}\text { Jiangsu Akcome Science\&Technology } \\
\text { Co.,ltd. }\end{array}$ & Solar \\
\hline 28 & 300001 & TRD & Qingdao TGOOD Electric Co.,Ltd. & Interactive Equipment \\
\hline 29 & 300014 & YWLN & EVE Energy Co.,Ltd. & Storage \\
\hline 30 & 300037 & $\mathrm{XZB}$ & Shenzhen Capchem Technology Co.,Ltd. & Storage \\
\hline 31 & 300068 & NDDY & Zhejiang Narada Power Source Co.,Ltd. & Storage \\
\hline 32 & 300073 & DSKJ & $\begin{array}{l}\text { Beijing Easpring Material Technology } \\
\text { Co.,Ltd. }\end{array}$ & Storage \\
\hline 33 & 300118 & DFRS & Risen Energy Co.,Ltd. & Solar \\
\hline 34 & 300124 & HCJS & Shenzhen Inovance Technology Co.,Ltd. & Interactive Equipment \\
\hline 35 & 300207 & XWD & Sunwoda Electronic Co.,Ltd. & Storage \\
\hline 36 & 300274 & YGDY & Sungrow Power Supply Co.,Ltd. & Comprehensive \\
\hline 37 & 600021 & SHDL & Shanghai Electric Power Co., Ltd. & Solar \& Wind \\
\hline No & Code & Abbreviation & Constituent Name & Sub-sector \\
\hline 38 & 600089 & TBDG & TBEA Co.,Ltd. & Solar \\
\hline 39 & 600151 & HTJD & $\begin{array}{l}\text { Shanghai Aerospace Automobile } \\
\text { Electromechanical Co.,Ltd. }\end{array}$ & Solar \\
\hline 40 & 600312 & PGDQ & Henan Pinggao Electric Co.,Ltd. & Interactive Equipment \\
\hline 41 & 600406 & GDNR & Nari Technology Co.,Ltd. & Comprehensive \\
\hline 42 & 600416 & XDGF & Xiangtan Electric Manufacturing Co.,ltd. & Comprehensive \\
\hline 43 & 600438 & TWGF & Tongwei Co.,Ltd. & Solar \\
\hline 44 & 600478 & KLY & Hunan Corun New Energy Co.,Ltd. & Storage \\
\hline 45 & 600482 & ZGDL & $\begin{array}{l}\text { China Shipbuilding Industry Group } \\
\text { Power Co.,ltd. }\end{array}$ & Storage \\
\hline 46 & 600525 & CYJT & Changyuan Group Ltd. & $\begin{array}{l}\text { Storage \& Interactive } \\
\text { Equipment }\end{array}$ \\
\hline 47 & 600549 & XMWY & Xiamen Tungsten Co.,Ltd. & Storage \\
\hline 48 & 600563 & FLDZ & Xiamen Faratronic Co.,Ltd. & Storage \\
\hline 49 & 600580 & WLDQ & Wolong Electric Group Co.,Ltd. & Interactive Equipment \\
\hline 50 & 600770 & ZYGF & Jiangsu Zongyi Co.,Ltd. & Solar \\
\hline 51 & 600869 & ZHNY & Far East Smarter Energy Co.,Ltd. & Comprehensive \\
\hline 52 & 600875 & DFDQ & Dongfang Electric Co., Ltd. & Comprehensive \\
\hline 53 & 600884 & SSGF & Ningbo Shanshan Co.,Ltd. & Solar \& Storage \\
\hline 54 & 600885 & HFGF & Hongfa Technology Co.,Ltd. & Interactive Equipment \\
\hline 55 & 601179 & ZGXD & China XD Electric Co.,Ltd. & Solar \& Wind \\
\hline 56 & 601222 & LYNY & Jiangsu Linyang Energy Co.,Ltd. & Solar \\
\hline 57 & 601311 & LYGF & Camel Group Co.,Ltd. & Storage \\
\hline 58 & 601727 & SHDQ & Shanghai Electric Group Co., Ltd. & Wind \& Nuclear \\
\hline 59 & 601877 & ZTDQ & Zhejiang Chint Electrics Co.,Ltd. & Solar \\
\hline 60 & 601908 & JYT & Beijing Jingyuntong Technology Co.,Ltd. & Solar \& Wind \\
\hline
\end{tabular}

